\title{
Realistic Independent Documentary: Four Springs
}

\author{
Liying Liu* \\ School of Grammar and Law, Nanchang Aviation University, Nanchang 330038, Jiangxi Province, China
}

*Corresponding author: Liying Liu, liuliying0329@163.com

\begin{abstract}
With the advancement of science and technology, photography has evolved from heavy technology to light equipment, allowing it to become more accessible to the general public. Therefore, the documentary may be separated from professional media organizations and transformed into a personal action. As a result, independent documentaries started to emerge. This is based on the bottom of society and focuses on the viewpoint of young people, who can actually reconstruct society. "Four Springs" is regarded as one of China's most outstanding works in the field of independent documentary.
\end{abstract}

Keywords: Documentary; Realism; Four Springs

Publication date: December 2021; Online publication: January 25, 2022

\section{Introduction}

"Four Springs" is a documentary that takes place in a real family. Director Lu Qingyi left home at the age of 15 and spent many years wandering in a faraway nation ${ }^{[1]}$. He cast his parents as the protagonists in a small Southern town, and over the course of four years, he meticulously documented their wonderful daily lives. He gently carved out how his parents dealt with the passage of time and the ups and downs of life in their own unique way in the lovely image of Guizhou's tranquil living.

\section{Realism in independent documentary}

The "imitation theory" established by Aristotle in Poetics in ancient Greece is the foundation of realism theory. To begin with, it explains the relationship between literature, art, and life, claiming that the actual world is the blueprint for art and literature, and that art is an imitation of the real world. He emphasized the fundamental element of Realism: "poetry" (writing and art) should expose the substance and rule of the phenomena, as well as recognize the inevitability and universality in the actions of particular characters. "Realism is not just the actuality of details, but also the realistic replication of typical personalities in a typical situation," Engels later stated ${ }^{[2]}$.

The mission of the birth of documentary film determines that it has the ability to show the phenomenon world. The mission of documentary is to extract the representative events in the society as truly as possible from an objective perspective by means of photography technology, and then reflect the common problems of the whole society ${ }^{[3]}$. Compared with other types of films, documentaries are more serious, authoritative or important. The reason why the author feels that documentaries carry more content lies in the relationship between documentaries and reality. In the period when independent documentaries have not yet developed, most of the production units of documentaries are media companies or television stations with sufficient financial and human support, which will inevitably be restricted by all parties, which will inevitably affect the reporting angle and even authenticity of documentaries. Independent documentaries are not subject to many constraints, so they can restore the truth and reflect the objectives of the world as much as possible. This is a major advantage of independent documentaries. 


\section{Realism in "Four Springs"}

The theme of director Lu Qingyi's film is his own family. He does not intrude in the family as an outsider, allowing for a true representation of the live situation in the photograph. The core of documentary authenticity is to use actual life as the material, real people and real events as the performance object, and to process and showcase it artistically in order to portray the essence of reality. The design isn't lavish, but the things are well-placed and surrounded by luscious flowers and plants. The two elderly people's lives are not sluggish. Everything is really romantic and suffused with smoke and rage. In the hospital, my parents danced, played the piano, and looked at flowers ${ }^{[4]}$. His mother focused on sewing, and his father played musical instruments at leisure. Sewing, watering flowers, growing vegetables, the mountains, fields and water of the small town, the bees and goldfish raised by his father, and the annual "guests" - is overall, these daily life scenes make the audience feel that everything in the film is like a familiar life.

The objective of realism is to illustrate the substance of life or the inevitable law, not to mechanically "photograph" the objective reality. Several of the Lu family's children return and go several times during the film. The mother will prepare a lot of food and clothing for each child before sending them off, and the father will accompany them. Children go great distances, leaving mainly their old parents behind in their hometown, which is thousands of miles away. This is a scenario that affects not only the Lu family, but many others throughout China. They're known as "empty nesters." It is not the goal of recording to fix the problem. The documentary is unable to provide us with an answer. It simply depicts the most typical circumstance beneath the lens and elicits emotional responses from the audience. Birth, old age and death are the most common pain in the world. The death of his sister accounts for most of the dark color of this documentary. Most individuals will have helplessness and pain in the face of illness. The film gives the audience an opportunity to think about life ${ }^{[5]}$.

The act of creative production is a process of decision-making, and decision-making is influenced by implicit value. Understanding the intrinsic interaction between characters and objects is crucial to grasping the heart of documentary authenticity. If there is no procedure for displaying meaningful content, we should not devote too much time and space to it; otherwise, we will lose sight of the recording's objective and relevance, and we will be unable to demonstrate its humanistic spirit and connotation. The documentary is based on true stories ${ }^{[6]}$. The death of my sister was the most significant event in "Four Springs." We might suppose that as a family member, he would be unable to remain detached from his family's joys and sorrows. "At the moment of death, go ahead and shoot, as merciless as a wolf," urged the director of "the universe of mankind." They consider themselves as robots without feeling in order to achieve authenticity, and their sense of morality as human beings should be forced buried at that time. All that matters is that objective reality be respected and pursued.

Long shots are also used in the film to show the film's reality. Long shots can preserve the flow of time and minimize the need for editing and space division. Its performance environment is based on actual reality and underlines the picture's inherent potency. As a result, it may demonstrate the ambiguity of existence and the multiple meanings of objects. As a result, many record film makers choose to employ long shots. In the film "Four springs," there are some extended moments that are very beautiful: On the right side of the picture, the dexterous mother is concentrated on stepping on the sewing machine, while on the left side, the versatile father is singing "friends" on the computer. A wall in the middle separates the two sections ${ }^{[7]}$. They are independent and together. This silent company at the same time and in the same place is really valuable. The audience can't help but move and sense the beauty and fascination of life when it's full of lyrical vitality.

The film also makes extensive use of visuals and metonymy. Swallows, for example, flew in on the day of their parents' golden wedding in the first spring. Swallows are currently carrying the message of "joy" in their films. When the sound and painting were out of sync in the second spring, the image showed 
the mother working in the kitchen, and the voice over was the father's voice urging the swallow to return ${ }^{[8]}$. Swallows are heralding the approach of spring right now. The sight of the swallow's return was exhibited in the third spring through a film from 2012, creating a feeling of nostalgia. The swallow returned to the nest in the fourth spring and peeked his head out. The camera was focused on his parents' happy faces. The illogical lens groups are tied together using time as the span, giving the "swallow" a distinct aesthetic vision that repeats repeatedly. The interplay with the director's subjective narrative perspective is particularly thought-provoking. "Swallow" is not only a sign of spring, but it also infiltrates its ideographic image into the picture language ${ }^{[9]}$.

\section{Authenticity and subjective consciousness}

It is undeniable that the real existence of documentaries is the subjective consciousness of editors and directors. The narrative structure of the film "Four Springs" is plate type. Each plate is interdependent and independent. It seems that there is no logical connection, but it has a relatively clear theme. It uses narratology theory to integrate the records of real life and achieve a seemingly random life flow, which is actually a conscious choice effect. When creating a documentary, we can observe it from different angles and value orientations, but in the end, the editor and director will determine a clear theme ${ }^{[10]}$. This process of choice which is no longer a simple objective reality, but full of the subjective will of the editor and director. In the shooting, the author believe that laughter and tears coexist in our parents' life every year, but what we see in the work is the pain in the middle and the laughter at the beginning and end, which is determined by the director's choice of material in the later editing. However, this subjective consciousness is implemented on the premise of respecting the truth, and its purpose is to better restore the truth.

\section{Conclusion}

Documentary should strive to present the potential reality. Under the guidance of realism theory, independent documentary has the ability to restore the original meaning of documentary. "Four springs" has played a good exemplary role in the development of China's independent documentary ${ }^{[11]}$. It is close to the ordinary life of the audience from the civilian perspective, and causes more psychological recognition of the audience from the records of the most familiar and natural scenery, things and characters, so as to achieve emotional resonance with the audience. This is the trend of the creation and dissemination of China's independent documentary.

\section{Disclosure statement}

The author declares that there is no conflict of interest.

\section{References}

[1] Yu S, 2020, Development and Innovation of Chinese Documentary Under Realistic Theory. Popular Literature and Art, 2020(03): 189-190.

[2] Yin Z, 2019, Creation and Dissemination of Chinese Independent Documentaries from the Perspective of Civilians - Taking Four Springs as an Example. Media Forum, 2019(23):182-183.

[3] Ian A, Wang C, 2013, Realism, Philosophy and Documentary. World film, 2013(01): 183-192.

[4] Pan M, 2019, The "True Expression" of Hand-Held Photography - An Interpretation of the Image Language of Four Springs. Film and Television Production, 2019(12): 85-89.

[5] Wang L, 2019, The Documentary Style of the Independent Documentary Four Springs. Young Journalist, 2019(35): 97-98. 
[6] Du X, You H, 2020, Public Communication Value and Ethical Dilemma of Private Documentary Four Springs. Sound Screen World, 2020(16): 68-69.

[7] Wu Y, 2020, Discussion on the Commercial Value Realization of the Content and Style of Four Springs from Poetic Realism. Global Premiere, 2020(5): 46-47.

[8] Luo Y, 2020, Alternative Aesthetics of Documentary - Taking Four Springs and Ladder of Heaven As Examples. Satellite TV and Broadband Multimedia, 2020(14): 126-128.

[9] Wang Y, 2019, Four Springs Waits for the Spring of the Documentary. Business Week (Chinese version), 2019(2): 12-14.

[10] Song W, 2019, The Cultural Dimension of the Documentary Four Springs: A Warm and Sentimental Journey Back to the Hometown. Film Review, 2019(6): 22-24.

[11] Zhang B, Pan T, 2019, Private Records and Life Images - Interpretation of the Documentary Film Four Springs. New Film, 2019(2): 80-85. 